\title{
A Cross-linguistic Study of English and Persian Prepositions
}

\author{
Seyedeh Sara Jafari \\ Department of Foreign Languages, Abadeh Branch, Islamic Azad University, Abadeh, Iran
}

\begin{abstract}
This paper has tried to show that the errors that Persian learners of English mostly commit in using English prepositions have root in their L1. In other words, using wrong preposition, addition of an unnecessary preposition, or deletion of prepositions are often because students tend to transfer their intended meanings to English in the same way they are expressed in Persian. Firstly, the word contrastive analysis was discussed in detail, history of contrastive analysis and two version of contrastive analysis were presented. Secondly a cross - linguistic analysis of English and Persian prepositions in the field of technology, computer, management, education, research, anthropology, psychology, philosophy, translation and semantic were discussed. Thirdly, the applied comparative and contrastive was discussed. 11 couples of technical words with their definitions have been randomly searched on the internet and selected. Fourthly, some predictions of errors in the process of learning were offered. Finally, some pedagogical explanations in order to show significant of contrastive analysis in language teaching were discussed. Results show that most Persian students who learn English language make these kinds of errors. Therefore, language teachers are highly recommended to guide their learners to prevent these errors and also to increase their chance of learning a language.
\end{abstract}

Index Terms-contrastive analysis, cross-linguistic analysis, language prepositions, EFL learners

\section{INTRODUCTION}

Contrastive analysis (CA) is the systematic study of a pair of languages with the purpose of identifying and describing their differences and similarities. CA hypothesis attempts to compare learners' L1 and L2 to explain possible difficulties that the learners might encounter in L2 learning situation. On the basis of CA, when learners try to learn L2, the patterns and rules of L1 may cause main difficulties to their L2 learning. This phenomenon, which is the main concept in CA, referred to as negative transfer (L1 interference) which means acquisition hindered where L1 and L2 differ. On the contrary, positive transfer takes place where features of the L1 and the L2 match and the acquisition of the L2 is facilitated. These difficulties can be predicted based on the systematic linguistic comparison of two languages.

The history of CA dates back to Robert Lado who is considered one of the founders of modern contrastive linguistics, which as a sub discipline of applied linguistics, aimed at improving language teaching materials. In his book "Across Cultures (1957)" Lado claimed that those elements in the target language which are similar to the learner's native language will be simple for him/her, and those elements that are different will be difficult. As Shidak Rahbarian, Mohammad Reza Oroji and Farnaz Fatahi say in their article "A Contrastive Study of English and Persian Double Object Construction", CA was used extensively in the field of Second Language Acquisition (SLA) in the 1960s and early 1970s, as a method of explaining why some parts of a target language were more difficult to acquire than others.

CA includes two versions, strong version and weak version. The strong version believes that difficulties in learning a language can be predicted based on a systematic comparison of the system of the learner's first language (its grammar, phonology and lexicon) with the system of a second language. It predicts that second language learners will have difficulty with parts which differ from their first language, but they will have no problems with elements which are similar in their first language. Lado have been associated with the strong version of the contrastive hypothesis. On the other hand, weak version believes that the analyzing and explaining of the errors must be only based on the observed interference phenomenon in a classroom situation. In contrast to strong version, the advocates of this version believe their claim has a diagnostic power rather than a predictive power.

A remarkable point to consider is how it is possible to compare and contrast two different languages while every language is a self-contained system. According to Krzeszowski (1990), comparison of two languages involves the basic assumption that the elements to be compared share something in common, against which differences can be stated. This common platform of reference is called "tertiumcomparationis". It shows that totally similar languages as well as totally different languages cannot be compared and contrasted. Therefore, the first significant point in the comparison of a pair of languages is to realize if they share some points of similarity.

Sometimes teachers should be a care about these kinds of errors that are made by Persian students who are learning English. According to Mahmoodzadeh (2012), teachers should be more aware about the errors of their students. According to this issue, Mahmoodzadeh, M. (2012) in his article "A Cross-linguistic Study of Prepositions in Persian 
and English", intends to investigate the errors made due to the cross-linguistic influence between the L1/SL and L2/TL language (i.e. Persian \& English).

In the present cross-linguistic study, meanwhile, the ideas of strong version have been followed. Since English and Persian languages share some points of similarity at their syntactic levels, the contrastive analysis have been done at syntactic level of the two languages, i.e., prepositions were selected as an element at the syntax of these languages to be compared and contrasted carefully. In the following section, the procedures of the current study will be described in details.

\section{THE STUDY}

Any systematic CA program follows certain steps and procedures as CA is a type of research that has to be conducted step by step, and systematically. The first step in a contrastive study is a thorough and systematic description of the two language systems. In this step, the contrastive linguist should see whether a particular subsystem of L1 is present in L2. If it isn't present in L2, the two languages cannot be compared for the lack of this common ground. If the subsystem in L1 is present in L2, then the researcher should check the distribution of items in both languages. In this respect, English and Persian languages both include prepositions at their syntactic levels.

In English, a preposition is an important part of speech which links nouns, pronouns, and phrases to other words in a sentence. It sits before a noun to show the noun's relationship to another word in the sentence. For example in "the eagle soared above the clouds", the preposition "above" shows the relationship between "clouds" and "soared". A preposition usually indicates the temporal, spatial or logical relationship of its object to the rest of the sentence (Guernier, P. Achieving equivalence at the level of grammar: a contrastive.

Study of the use of prepositions in English and French). For instance, 'the book is on the table'. Prepositions are classified as simple (single word) and compound (more than one word) like, in between, except for, because of, on behalf of, etc. The following words are the most common prepositions in English: above, about, across, after, against, along, among, around, at, before, behind, below, beneath, beside, between, beyond, by, despite, down, during, except, for, from, in, inside, into, like, near, of, off, on, onto, out, outside, over, since, past, till, to, toward, though, throughout, under, underneath, until, up, upon, with, within and without.

On the other hand, a preposition in Persian is an important word which comes to show the functions of other words in a sentence. It does not have an independent meaning, and it functions as a demonstrator or of the function of words preceding and following it in a given sentence. From one perspective, prepositions in Persian, like English, are categorized into simple prepositions consisting of a single word such as "az, be, dar" and complex prepositions that include a group of words that act as one unit. For example, درمقابل ، بعد از ، بِ

Generally speaking, Persian prepositions are divided into two categories: those that come before the words and those that come after the words, like the "Ra" (\lrcorner$)$ marker that whenever follows a noun, the noun is the direct object of the sentence. However, English does not have the second type of prepositions, i.e., the prepositions in English generally precede their objects. This indicates that the order of using prepositions in the two languages differ in some cases,

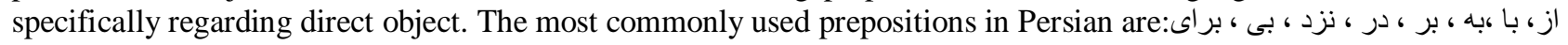

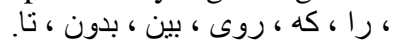

After examining the presence and distribution of items through the description of the 2 language systems, the linguist has to select the two subsystems and the items to be compared and contrasted. In this study, it was decided to select prepositions as part of the syntactic levels of English and Persian to be compared .To this end, 11 couples of technical words with their definitions have been randomly searched on the internet and selected. The definitions that had been chosen from online dictionaries and standard texts on the World Wide Web were written in the standard form of both languages and were in the same level. They were put in an order so that every English word's definition could be compared with its equivalent word's definition in Persian. Notice that the title of each Persian paragraph is the Persian equivalence of the title of the preceding English paragraph; however, every paragraph itself is a dictionary entry or a text description of its title, so the paragraphs are not equivalent or translated in the two languages.

The primary purpose of this limited study was to conduct a cross - linguistic analysis of English and Persian in a syntactic category - prepositions - that both share in order to investigate what kinds of problems a native speaker of Persian may encounter when learning English as $\mathrm{L}_{2}$. In fact, the probable types of difficulties of a learner in using English prepositions would be predicted at the end. In the following section, the paragraphs under investigation can be observed with the underlined and bolded prepositions in English and Persian languages.

\section{A. Technology}

1. The branch of knowledge that deals with the creation and use of technical means and their interrelation with life, society, and the environment, drawing upon such subjects as industrial arts, engineering, applied science, and pure science.

2. The terminology of an art, science etc.; technical nomenclature.

3. A technological process, invention, method, or the like.

4. The sum of the ways in which social groups provide themselves with the material objects of their civilization. (dictionary.com) 
Example Sentence

He writes often about science, technology, and public health. (dictionary.com)

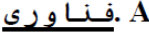

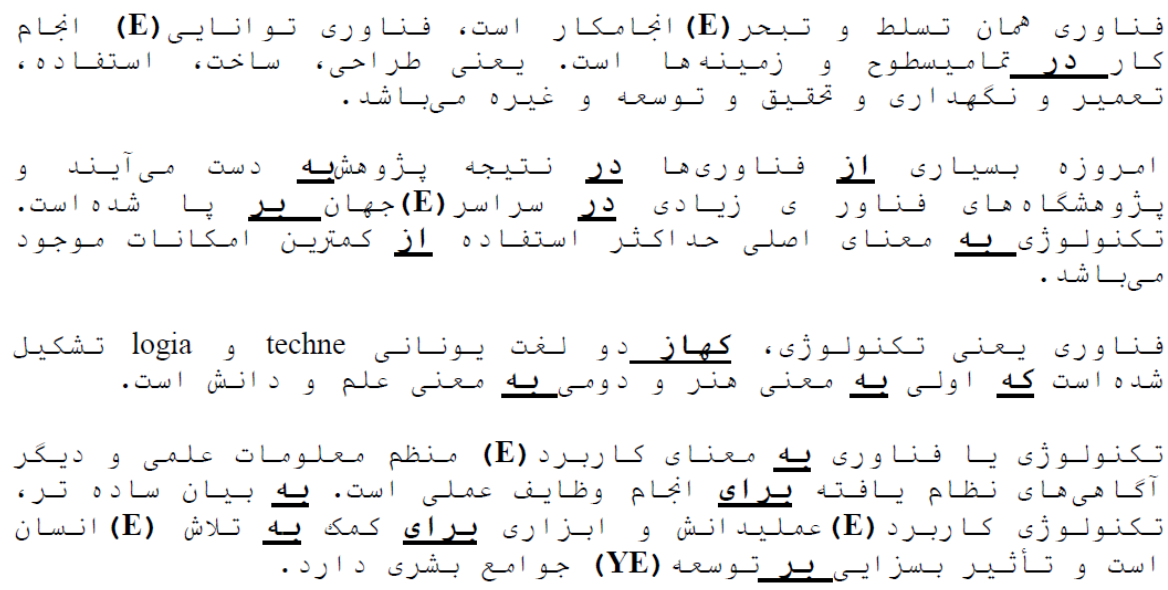

\section{B. Computer}

1. Also called processor, an electronic device designed to accept data, perform prescribed mathematical and logical operations at high speed, and display the results $\underline{\text { of }}$ these operations. Compare analog computer, digital computer.

2. A person who computes; compotes. (dictionary.com)

Example Sentences

- File sharing was originally intended to help people move data across computer networks.

- Actual data will only continue to match the computer models anyhow. (dictionary.com) 

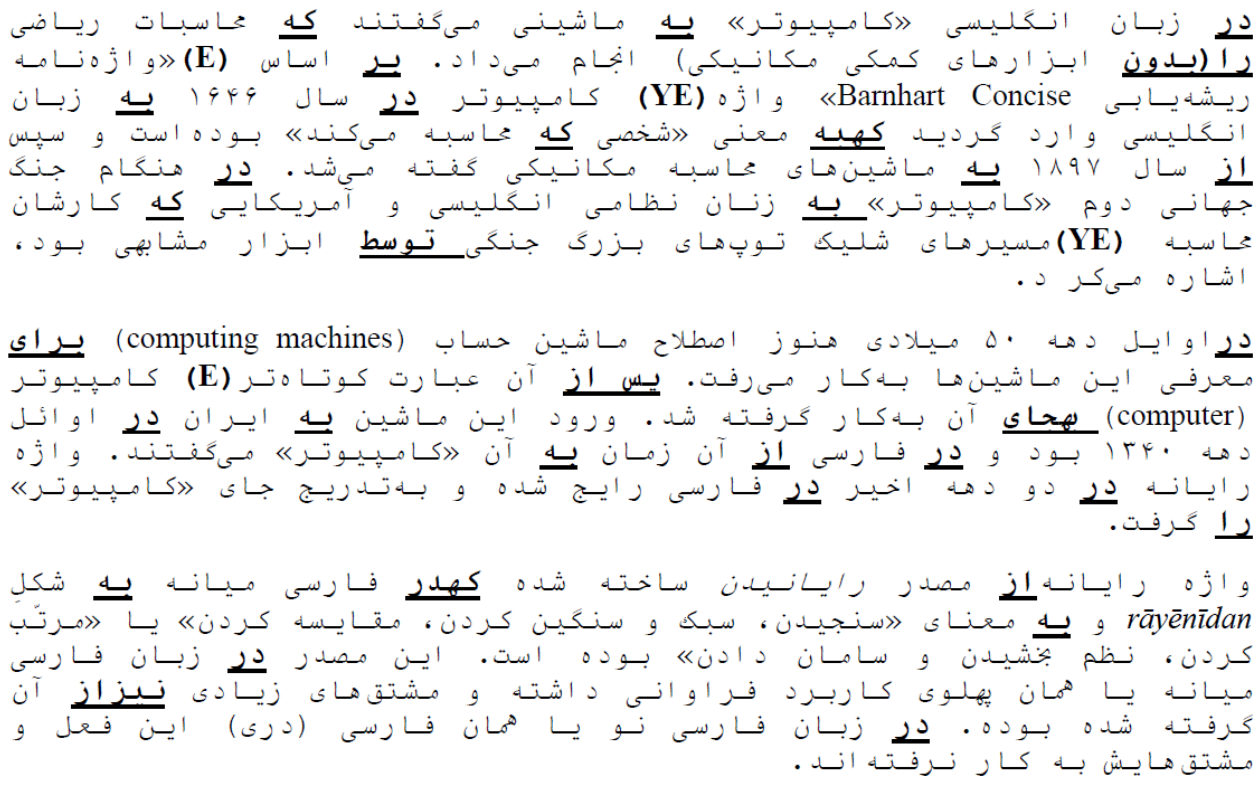

\section{Management}

1. The act or manner of managing; handling, direction, or control.

2. Skill in managing; executive ability: great management and tact.

3. The person or persons controlling and directing the affairs of a business, institution, etc.The store is under new management.

4. Executives collectively, considered as a class (distinguished from labor). (dictionary.com) 


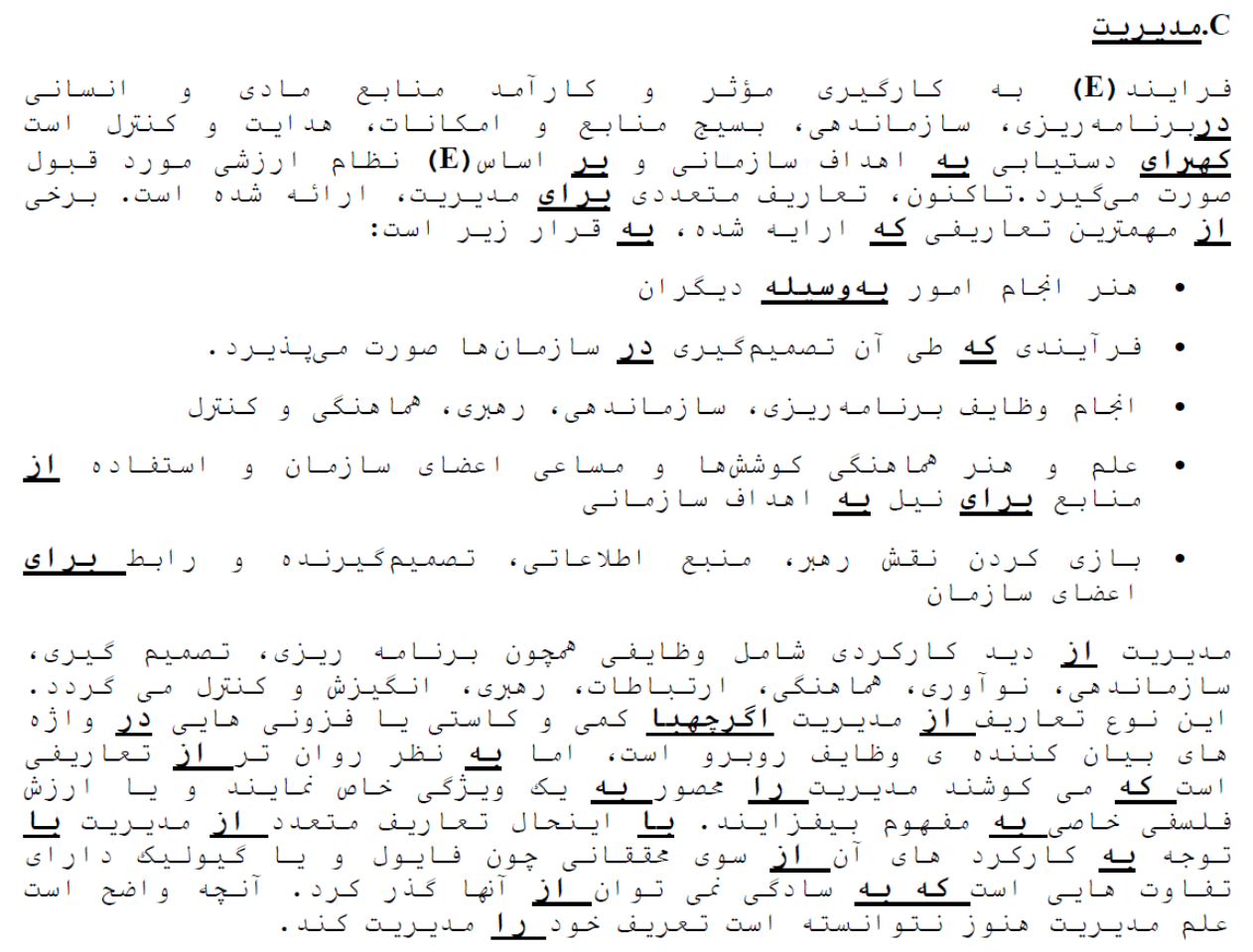

\section{Education}

1. The act or process of educating or being educated.

2. The knowledge or skill obtained or developed by a learning process.

3. A program of instruction of a specified kind or level: driver education; a college education.

4. The field of study that is concerned with the pedagogy of teaching and learning.

5. An instructive or enlightening experience: Her work in the inner city was a real education. (dictionary.com)

Education in its broadest, general sense is the means through which the aims and habits of a group of people lives

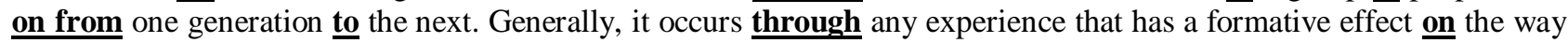
one thinks, feels, or acts. In its narrow, technical sense, education is the formal process by which society deliberately transmits its accumulated knowledge, skills, customs and values from one generation to another, e.g., instruction in schools. (dictionary.com)

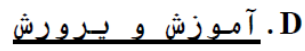

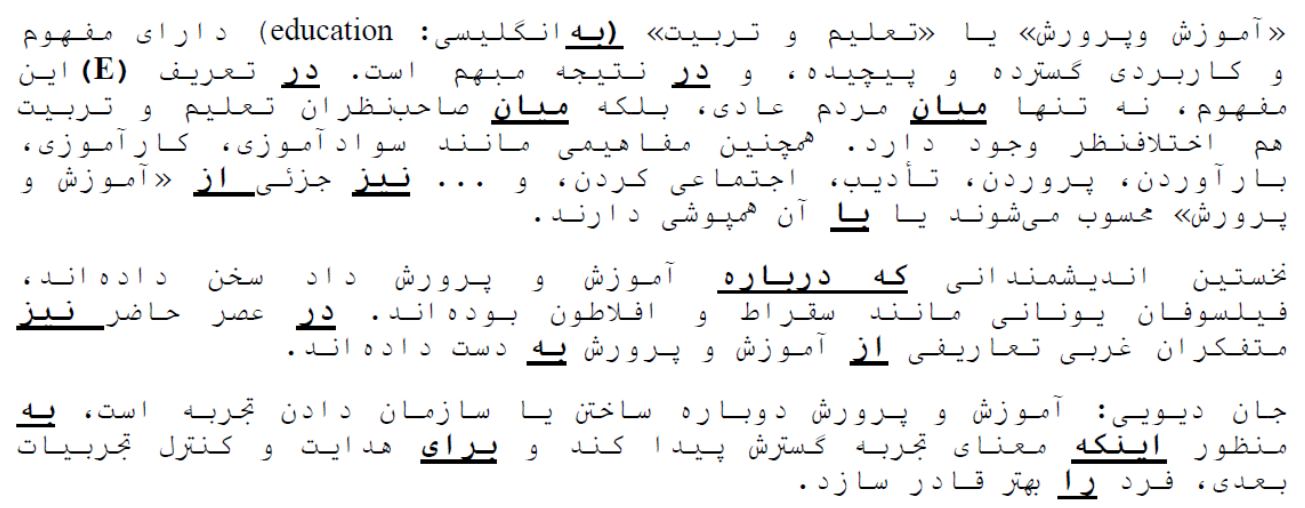

\section{E. Research}

Disquisition - A diligent or systematic search, a thorough investigation or research. Primary - A direct source of information or research, a document not emended by Secondary source - Information or research that is derivative, such as a comment by historian, an encyclopedia article, or a critical essay. Rh factor - Named for the rhesus monkeys used in research to identify blood types. All effort directed toward increased knowledge of natural phenomena and environment and toward the solution of problems in all fields of science. This includes basic and applied research. (dictionary.com)

The word "research" is used to describe a number of similar and often overlapping activities involving a search for information. For example, each of the following activities involves such a search; but the differences are significant and worth examining. (dictionary.com) 


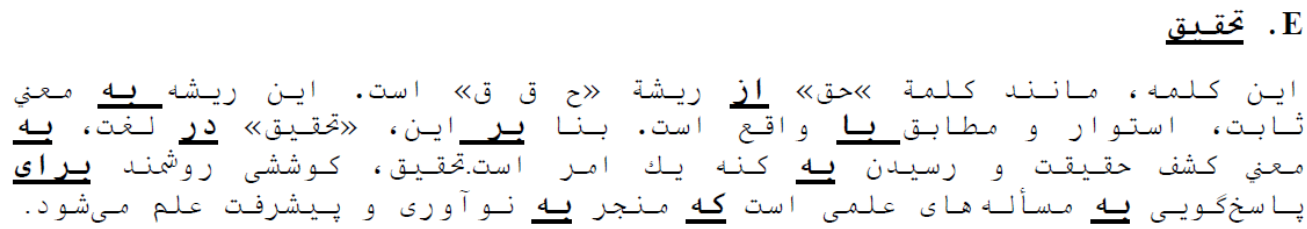

\section{F. Anthropology}

1. The science that deals with the origins, physical and cultural development, biological characteristics, and social customs and beliefs of humankind.

2. The study of human beings' similarity to and divergence from other animals.

3. The science of humans and their works.

4. Also called philosophical anthropology. The study of the nature and essence of humankind. (dictionary.com)

5. The scientific study of humans, especially of their origin, their behavior, and their physical, social, and cultural development.

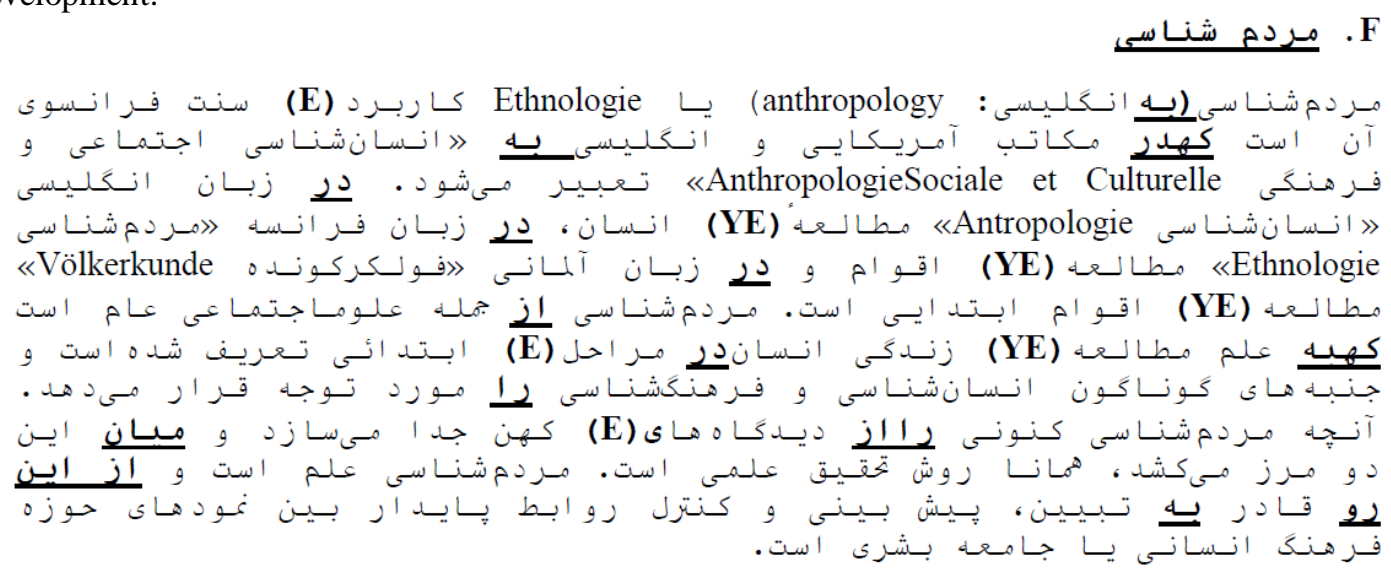

\section{G. Psychology}

1. The science of the mind or of mental states and processes.

2. The science of human and animal behavior.

3. The sum or characteristics of the mental states and processes of a person or class of persons, or of the mental states and processes involved in a field of activity: the psychology of a soldier; the psychology ofpolitics.

4. Mental ploys or strategy: He used psychology on his parents to get a larger allowance. (dictionary.com)

The science dealing with mental phenomena and processes. Psychologists study emotions, perception, intelligence, consciousness, and the relationship between these phenomena and processes and the work of the glands and muscles. Psychologists are also interested in diseased or disordered mental states, and some psychologists provide therapy for individuals. In the United States, however, psychologists, unlike psychiatrists, are not medical doctors. (dictionary.com)

Note: The two main divisions of psychology are individual or personality psychology and social psychology; social psychology deals with the mental processes of groups. (dictionary.com)

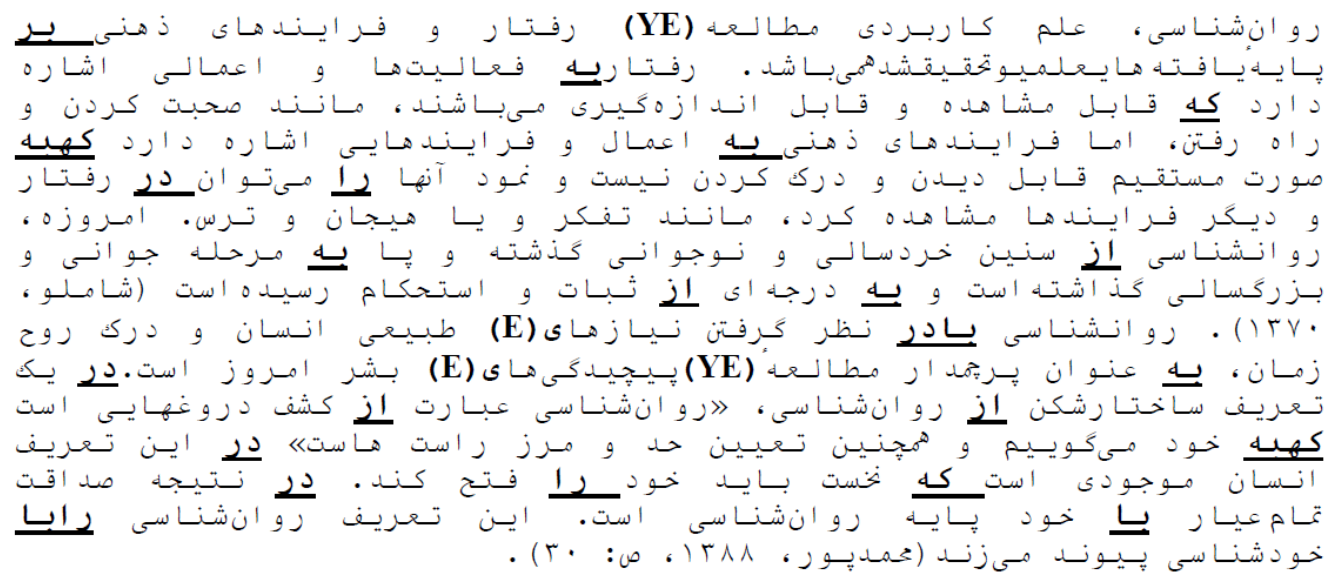

\section{H. Philosophy}

Philosophy is the study of general and fundamental problems, such as those connected with reality, existence, knowledge, values, reason, mind, and language. Philosophy is distinguished from other ways of addressing such 
problems by its critical, generally systematic approach and its reliance on rational argument. The word "philosophy"

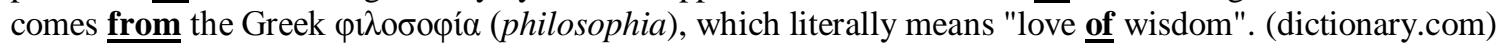

H

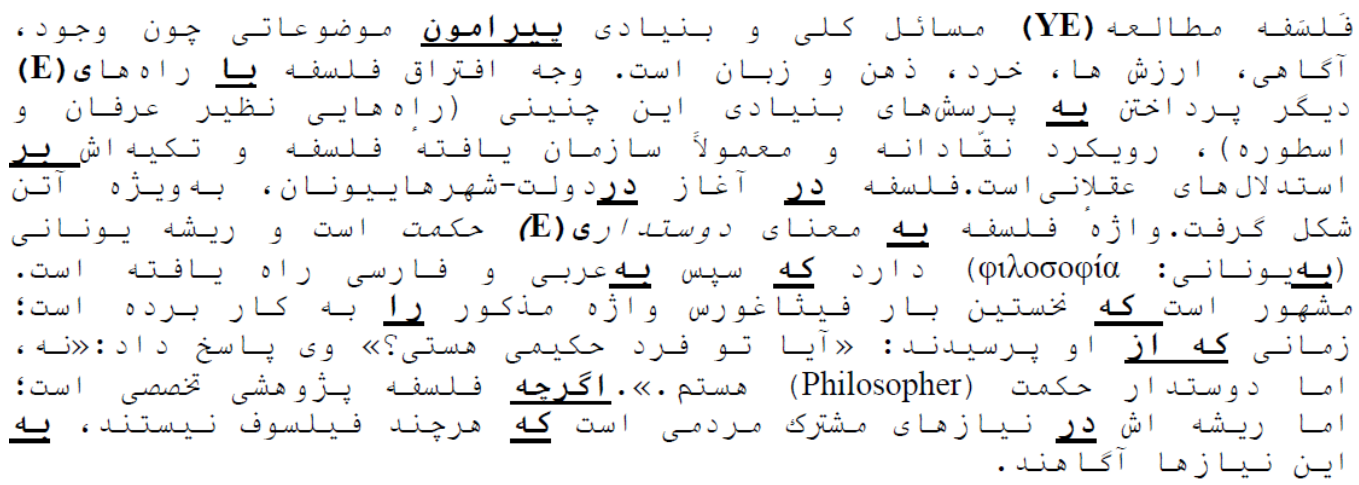

\section{Translation}

Translation is the communication of the meaning of a source-language text by means of an equivalent targetlanguage text. Whereas interpreting undoubtedly antedates writing, translation began only after the appearance of written literature; there exist partial translations of the Sumerian Epic of Gilgamesh (ca. 2000 BCE) into Southwest Asian languages of the second millennium BCE. (dictionary.com)

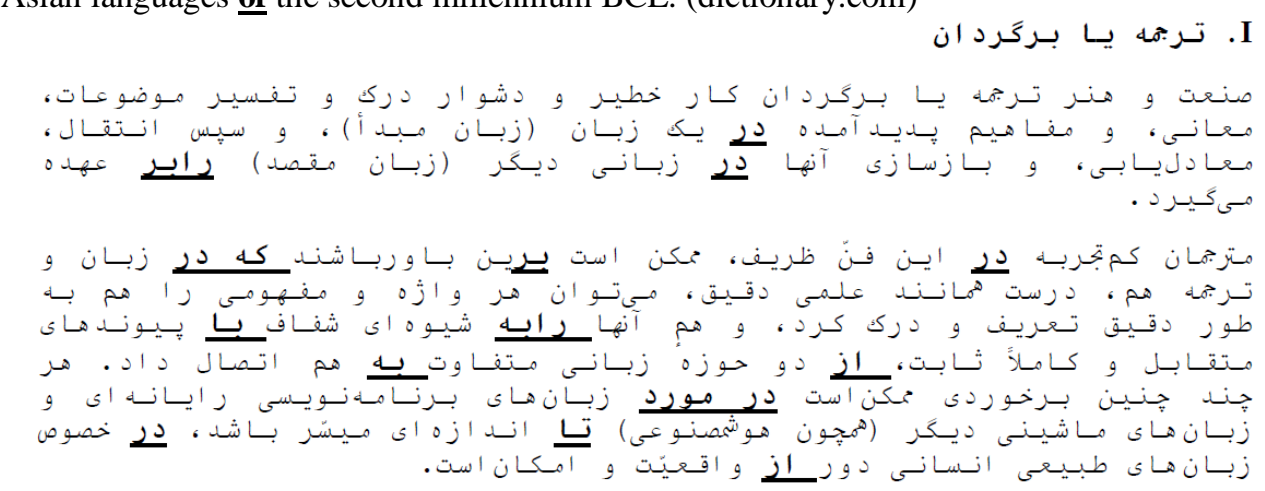

\section{J. Semantics}

Semantics (from Greek: sēmantiká, neuter plural of sēmantikós) is the study of meaning. It focuses on the relation between signifiers, such as words, phrases, signs, and symbols, and what they stand for, their denotata. Linguistic semantics is the study of meaning that is used to understand human expression through language. Other forms of semantics include the semantics of programming languages, formal logics, and semiotics. (dictionary.com)

$$
\text { J مـنـا }
$$

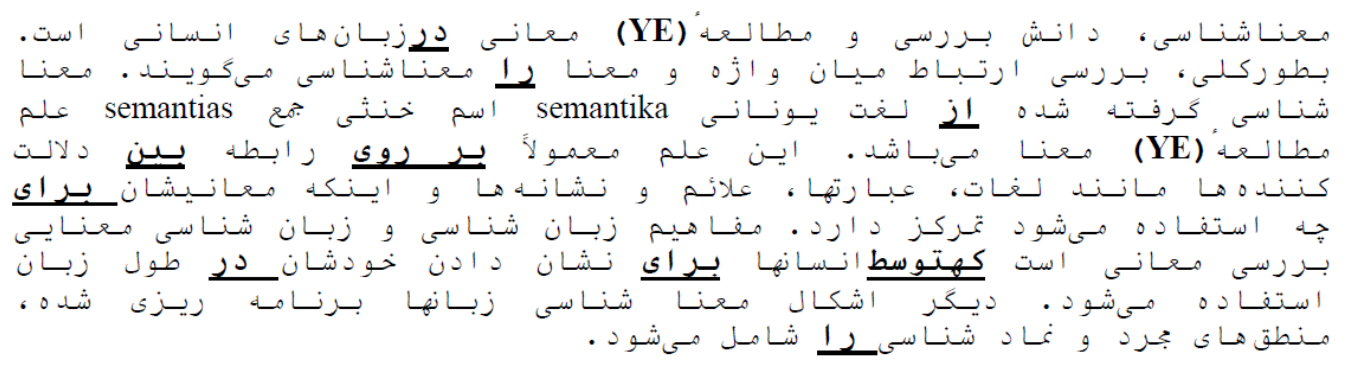

\section{COMPARISON AND CONTRAST}

As it is observed, a number of prepositions have been found in each English and Persian paragraph. It reveals that prepositions are parts of speech that are frequently used in most of the sentences in English and Persian. After recognizing all prepositions in paragraphs, the frequency of each preposition was calculated. The total number of prepositions used in all English paragraphs was 126 and the total number of them in Persian paragraphs was 216 . In the following, the frequency of each preposition is demonstrated.

\section{A. Total Number of English Prepositions}

Of $=59$ with $=8$ in $=14$ at $=2$ into $=1$ for $=4$ upon $=1$ across $=1$ about $=2$ under $=1$ from $=8$ to $=6$ on $=5$ by $=5$ toward $=2$ between $=2$ after $=1$ through $=3$ 


\section{B. Total Number of Persian Prepositions}

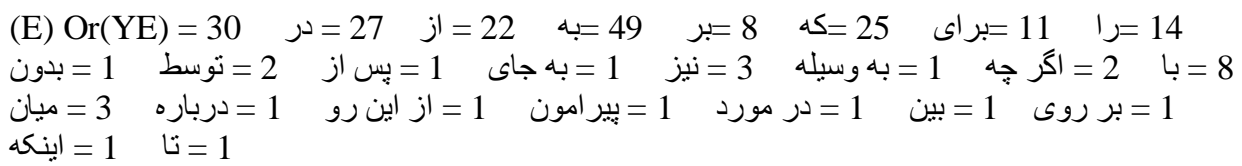

The most frequently used preposition in English was ' of ' firstly ; then there were " in, with, from , to , by , on , for , through, about, between, at, toward, into , after , under , across , and upon”, respectively.

It is said that there are almost 150 prepositions in English. Since the collected data for the Present study indicates, the most common prepositions used in English sentences are 'of, In,with,to,by,on,etc.' that are 18.On the other hand, 216 prepositions were generally founded in Persian paragraphs from Which the most frequently used was بـ , then they

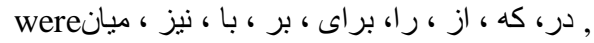

It is important to notice that (E) or (YE) is not a preposition in Persian, but it is called 'Naghshnemaye Ezafe 'which comes to add one word to the next in order to connect them together. Therefore, it was considered important because it is the semantic equivalent of some English prepositions mostly 'of'. Most of these prepositions are semantically equivalent in the two languages. Possible equivalent prepositions can be seen below:

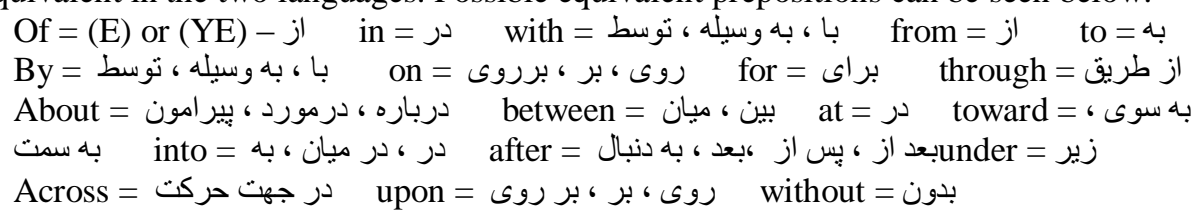

In regard to strict rules of English and Persian for using prepositions correctly in sentences and also regarding the above mentioned semantic equivalents, some probable errors of $\mathrm{L}_{2}$ learners of English will be predicted in the following section.

\section{PREDICTION OF LEARNERS' ERRORS}

One of the common errors that a Persian speaker may commit in the process of learning English as a $\mathrm{L}_{2}$ may be that the learners may tend to use a preposition where there is no need to use it. As the collected data indicated, the reason is that the number of prepositions used in Persian is more than the number of them in English. It seems that few sentences without any preposition can be found in Persian. Therefore, learners may tend to add an unnecessary preposition (about) to the verb 'discuss' which does not have any specific preposition in the following sentence : 'I discussed about my problems in the classroom. ${ }^{*}$ In such a situation students usually look for an appropriate semantic equivalent to express their idea completely. So, they may choose 'about', an unnecessary addition, to say 'درباره which causes an error.

In English, it is a rule that two prepositions cannot follow each other in a sentence, however it is possible in Persian and there is no such a rule in Persian language. Notice that a preposition like 'into' in English consists of two prepositions of 'in' and 'to', but it works as a single preposition and does not reject the rule. In paragraph 6, line 6, the following sentence includes two separate prepositions one comes after another: آنجه مردم شناسى كنونىيرا إز ديدكاه هايكهن جدا This point can cause $\mathrm{L}_{2}$ learners to do the same thing in an English sentence, i.e., to bring a preposition after the other preposition and make an error.

The other remarkable point is that some of English prepositions have more than one Persian equivalent. For instance, 'of' has two semantic equivalents: sometimes Naghshnemaye Ezafe (E) and other times, 'j', but there is no such a Naghshnema among English prepositions. This can make learners commit some errors. In this condition, the learners have to unlearn Naghshnemaye Ezafe because it is not included in the list of English prepositions.

According to Burt and Kiparsky (1975), it is a strict rule in English that after prepositions, a complement takes the gerund form or a nominal form. If the complement of a preposition is a verb, it should appear in its gerund form. A possible difficulty that the $\mathrm{L}_{2}$ learners may encounter here is with 'to' that sometimes can be troublesome. 'To' when used as an infinitive attached is not considered a preposition, so the following verb has to be appeared in its base form. But as a preposition, 'to' belongs to the first verb; in that it is necessary to complete the verbs meaning and so should be followed by a gerund instead of an infinitive. Therefore, 'to' is not a plain infinitive attached, as some students think. A $\mathrm{L}_{2}$ learner, thus, can make the following errors:

His behavior will lead to go to prison.* (going)

We look forward to seeyou.* (seeing)

At semantic level, sometimes students may have problem with finding right English equivalents for Persian prepositions. It can be a cause for making some common errors in using prepositions. For instance, more than one English equivalent exists for the same meaning in Persian. g., 'with' and 'by' both mean با ، به وسيله ، توسط which may cause the following error: I played football by myfriend.* (with). This is one of the most common errors that Persian students usually make. Other examples are 'of \& from' and 'in \& at' that each one can be used wrongly instead of the other.

There are many verbs in English that have their own specific preposition. Because students may be unaware of the preposition of a certain verb in English, they may transfer their intended meaning from their mother tongue to English by using a wrong preposition. For example: 


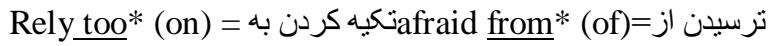

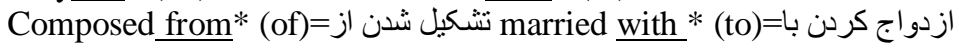

Most of the predicated errors are rooted in transferring concepts from Persian to English which causes interference in the process of learning.

\section{Significance of CA in Language Teaching (Pedagogical Exploitations)}

As CA is considered significant in its applied form, it must be borne in mind that it provides insights and carries implications for teaching (Wilkins, 1972, as cited in James, 1980). Applied CA can benefit from consequences of theoretical CA. Therefore applied CAs are interpretations of theoretical CAs rather than independent executions, as James (1980) notes. Teachers will be able to apply theoretical CA to predict some errors that may be committed by learners of English as a $L_{2}$. They have to notice that it can be difficult and confusing for students to keep their first language system in mind and to add a completely new language system to it as well. This is due to the fact that the components of learners' $\mathrm{L}_{1}$ (Persian) don't simply fit the system of $\mathrm{L}_{2}$ (English). Understanding the systematicity and separation of languages is a remarkable responsibility of language teachers since they have to bear in mind that every language learner is a single individual who should learn two self-contained language systems. By predicting learners' possible errors and understanding language transfer mechanisms, the teachers would be able to handle both language systems in the process of learning.

the most efficient materials are those based on a scientific description of the language to be learned, carefully compared with a parallel description of the native language of the learner (James, 1980). With respect to this point, careful comparison of $\mathrm{L}_{1}$ and $\mathrm{L}_{2}$ can enable material designers to devise materials and learning activities that can control learners' errors in a right way.

\section{CONCLUSION}

The findings of this limited cross-linguistic study show that the errors that Persian learners of English mostly commit in using English prepositions have root in their $\mathrm{L}_{1}$. In other words, using wrong preposition, addition of an unnecessary preposition, or deletion of prepositions are often because students tend to transfer their intended meanings to English in the same way they are expressed in Persian. This is the primary reason of making errors in using prepositions at syntactic level of both languages. However, it does not mean that all committed errors are because of $\mathrm{L}_{1}$ interference; sometimes $\mathrm{L}_{2}$ learners make errors due to their lack of knowledge. E.g., they use a wrong preposition for a specific verb because they simply don't know what the right preposition for that verb is. In contrast to CA beliefs, it may not be reasonable to recognize $\mathrm{L}_{1}$ interference as the mere source of $\mathrm{L}_{2}$ learners 'errors. In this regard, careful examinations of learners $\mathrm{L}_{1}$ and $\mathrm{L}_{2}$ and careful observation of errors in classroom environment are required to realize what other sources of errors exist in learning a language as a $\mathrm{L}_{2}$.

\section{REFERENCES}

[1] Asma, T. (2010). Transfer of simple prepositions from standard Arabic into English: The case of third year LMD students of English language at Mentouri University-Constantine. Unpublished M.A. Thesis. Mentouri University-Constantine, Algeria.

[2] Brown, H. D. (2000). Principles of language learning and teaching (4thed.). San Francisco State University: Pearson Education Limited.

[3] Burt, M., \&Kiparsky, C. (1975).The Goof icon: a repair manual for English. U.S.A: Newbury House Publisher.

[4] Danesi, M. (2003). Second Language Teaching: A View from the Right Side of the Brain. The Netherlands: Kluwer Academic Publishers.

[5] Danesi, M. (2000). Semiotics in language education. Berlin: Mounton de Gruyter.

[6] Erdogan, (2005). Contribution of error analysis to foreign language teaching. Mersin University Journal of the Faculty of Education, 1(2), 261-270.

[7] Guernier, P. Achieving equivalence at the level of grammar: a contrastive study of the use of prepositions in English and French.

[8] Hasan, A., \& Abdullah. I. (2009). The conceptual mapping of the English preposition into Arabic. European Journal of Social Sciences, 4(8), 604-613.

[9] James. C. (1980).Contrastive Analysis. Singapore: Longman.

[10] Krzeszowski, T.P.( 1990). Contrasting Languages: The Scope of Contrastive Linguistics.Mouton de Gruyter.

[11] Lado, R(1957). Across Cultures.

[12] Mahmoodzadeh, M.(2012). A Cross-linguistic Study of Prepositions in Persian and English: The Effect of Transfer.ACADEMY PUBLISHER Manufactured in Finland,Vol. 2, No. 4, pp. 734-740.

[13] Oller, J. W. \& Ziahosseiny, S. (1970). The contrastive analysis hypothesis and spelling errors. Language Leaning, 20, $183-189$.

[14] Pittman, G. A. (1966). Activating the use of prepositions. London: Longman.

[15] Quirk, R. et al. (1993). A University Grammar of English. London: Longman.

[16] Rahbarian,SH. Oroji, M \& Fatahi, F(2013). A Contrastive Study of English and Persian Double Object Construction. Frontiers of Language and Teaching. Volume 4 (2013).

[17] Richards, J. C. \& Schmidt, R. (2002). Longman dictionary of language teaching and applied linguistics (3rd Ed.). Malaysia: Pearson Education Limited. 
[18] Russo, G. A. (1997). A conceptual fluency framework for the teaching of Italian as a second language. Unpublished Doctorial Dissertation. University of Toronto, Canada.

[19] Selinker, L. (1972). Interlanguage. International Review of Applied Linguistics, 10(3), 209-231.

[20] Stern, H. H. (1983). Fundamental concepts of language teaching. Oxford: Oxford University Press.

[21] Talebinezhad, M. R. (2007). Conceptual fluency and metaphorical competence in second language acquisition: Two sides of the same coin? Journal of social Sciences and Humanities of Shiraz University, 26(4), 87-106.

[22] Talebinezhad, M. R. \& Hashemian, M. (2006). The development of conceptual fluency and metaphorical competence in L2 learners. Iranian Journal of Applied Linguistics, 9(1), 73-99.

[23] Takahaski, G. (1969). Perceptions of space and function of certain English prepositions. Language Learning, 19, $217-234$.

[24] http://dictionary.reference.com/browse/technology (accessed 3/4/2014).

[25] http://dictionary.reference.com/browse/public+health (accessed 3/4/2014).

[26] http://dictionary.reference.com/browse/computer (accessed 3/4/2014).

[27] http://www.reference.com/example-sentences/computer (accessed 3/4/2014).

[28] http://dictionary.reference.com/browse/management (accessed 3/4/2014).

[29] http://www.thefreedictionary.com/education (accessed 3/4/2014).

[30] http://www.thesimonfirm.com/teaching.html (accessed 3/4/2014).

[31] http://www.thefreedictionary.com/research (accessed 3/4/2014).

[32] http://www.webpages.uidaho.edu/info_literacy/modules/module2/2_1.htm (accessed 3/4/2014).

[33] http://dictionary.reference.com/browse/anthropology (accessed 3/4/2014).

[34] http://dictionary.reference.com/browse/psychology (accessed 3/4/2014).

[35] http://dictionary.reference.com/browse/pre+psychology (accessed 3/4/2014).

[36] http://en.wikipedia.org/wiki/Philosophy (accessed 3/4/2014).

[37] http://en.wikipedia.org/wiki/Translation (accessed 3/4/2014).

[38] http://en.wikipedia.org/wiki/Semantics (accessed 3/4/2014).

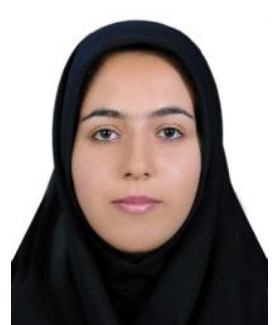

Seyedeh Sara Jafari received her B.A. degree in TEFL from Sheikhbahaee University, Isfahan, Iran. She continued her M.A. in TEFL at Azad University, Abadeh, Iran. She has been teaching English to Iranian EFL learners at several language institutes for more than four years. She has also taught General English courses at Azad University of Safashahr, Fars. Now, she is the deputy of research department of kharazmi-international institute in safashahr, Fars. As a researcher, she has contributed to some local and international journals such as national conferences in Iran, journal of English teaching in Iran, Journal of Language Teaching and Research, theory and practice in language studies, and Horizon Research Publishing, USA (HRPUB).Her main areas of interest include second language acquisition, first language acquisition, language teaching methodology, the role of affective variables in language teaching, psycholinguistic and contrastive analysis. 